\title{
Emerging Pharmacologic Therapies for Constipation-predominant Irritable Bowel Syndrome and Chronic Constipation
}

\author{
Shanti Eswaran, Amanda Guentner and William D Chey*
}

University of Michigan Health System, Ann Arbor, MI, USA

Irritable bowel syndrome with constipation and chronic functional constipation are common digestive disorders that negatively impact quality of life and account for billions of dollars in health care costs. Related to the heterogeneity of pathogenesis that underlie these disorders and the failure of symptoms to reliably predict underlying pathophysiology, traditional therapies provide relief to only a subset of affected individuals. The evidence surrounding new and emerging pharmacologic treatments, which include both luminally and systemically acting drugs, is discussed here. These include agents such as lubiprostone, bile acid modulations, guanylate cyclase-C receptor agonists, serotonin receptor modulators and herbal therapies.

(J Neurogastroenterol Motil 2014;20:141-151)

Key Words

Bile acid and salts; Constipation; Irritable bowel syndrome; Laxatives; Therapeutics

\section{Introduction}

Both chronic constipation (CC) and irritable bowel syndrome (IBS) are highly prevalent, heterogeneous functional disorders that affect approximately 10-20\% of the North American population. $^{1,2}$ The global prevalence of IBS ranges from $1 \%$ to $45 \%$, and seems to vary by geographic location, diagnostic criteria, age, gender and duration of symptoms. ${ }^{3}$ Typically, IBS is classified as diarrhea-predominant, constipation-predominant (IBS-C) or mixed type. ${ }^{4}$ These different IBS phenotypes likely have different pathophysiologies, and it seems reasonable that the approach to treatment should be phenotype-specific. In years past, therapy has been symptom-based, but as researchers' understanding of the disease advances, more specific therapies are being developed. This article summarizes current and emerging therapies for IBS-C and CC (Table).

\section{Overlap Between Constipation- predominant Irritable Bowel Syndrome and Chronic Constipation}

The Rome III classification system treats functional constipation (FC) and IBS-C as distinct disorders, the primary distinc-

Received: September 28, 2013 Revised: November 7, 2013 Accepted: November 20, 2013

(c) This is an Open Access article distributed under the terms of the Creative Commons Attribution Non-Commercial License (http://creativecommons. org/licenses/by-nc/3.0) which permits unrestricted non-commercial use, distribution, and reproduction in any medium, provided the original work is properly cited.

*Correspondence: William D Chey, MD, AGAF, FACG, FACP

Division of Gastroenterology, University of Michigan Health System, 3912 Taubman Center, SPC 5362, Ann Arbor, MI 48109-5362, USA

Tel: +1-734-936-6400, Fax: +1-734-936-7392, E-mail: wchey@umich.edu

Financial support: None.

Conflicts of interest: None.

Author contributions: All authors contributed extensively to the manuscript. Shanti Eswaran primarily drafted and prepared the document; Amanda Guentner helped write and edit the paper; William D Chey conceived and edited the manuscript. 
Table. Emerging Constipation-predominant Irritable Bowel Syndrome Therapies Advantages/Disadvantages

\begin{tabular}{|c|c|c|c|}
\hline Drug Class & Name & Advantages & Disadvantages \\
\hline \multirow[t]{2}{*}{$\begin{array}{l}\text { Bile acid } \\
\text { modulators }\end{array}$} & $\mathrm{CDCA}$ & $\begin{array}{l}\text { Double-blind placebo-controlled study showed } \\
\text { acceleration in colonic transit and improved } \\
\text { bowel function in } 36 \text { IBS-C patients. }\end{array}$ & $\begin{array}{l}\text { Lower abdominal cramping/pain in over } 40 \% \\
\text { of patients }\end{array}$ \\
\hline & Elobixibat (A3309) & $\begin{array}{l}\text { Three phase II trials in CC patients report } \\
\text { improvement in the number of SBMs, stool } \\
\text { consistency and decrease in straining. }{ }^{6-8}\end{array}$ & $\begin{array}{l}\text { No consistent amelioration of abdominal pain } \\
\text { or bloating, except at the } 15 \mathrm{mg} \text { dose }\end{array}$ \\
\hline $\begin{array}{l}\mathrm{GC}-\mathrm{C} \text { receptor } \\
\text { agonist }\end{array}$ & Plecanatide & $\begin{array}{l}\text { Phase III, } 12 \text { week trial comparing plecanatide vs. } \\
\text { placebo in } 951 \mathrm{CC} \text { patients reported that } 21.5 \% \\
\text { vs. } 11.5 \%(P=0.003) \text { were responders. }\end{array}$ & $\begin{array}{l}\text { Status as a treatment option still unknown, } \\
\text { especially for IBS-C }\end{array}$ \\
\hline \multirow[t]{3}{*}{$\begin{array}{l}\text { Serotonin } \\
\text { modulators }\end{array}$} & Prucalopride & $\begin{array}{l}\text { Three placebo-controlled trials in CC demon- } \\
\text { strated a significant increase in the proportion of } \\
\text { patients achieving at least } 3 \mathrm{SBMs} \text { per week. }{ }^{10-12}\end{array}$ & Very limited data on the impact in IBS-C \\
\hline & Mosapride & $\begin{array}{l}\text { Generally well tolerated and shown in one small } \\
\text { prospective pilot study to improve symptoms. }\end{array}$ & $\begin{array}{l}\text { One small underpowered placebo controlled } \\
\text { trial demonstrated no difference in IBS-C }{ }^{13} \\
\text { no published studies have adequately ad- } \\
\text { dressed the role of mosapride in the mana- } \\
\text { gement of IBS-C. }\end{array}$ \\
\hline & $\begin{array}{l}\text { Pumosetrag } \\
(\mathrm{MKC}-733)\end{array}$ & $\begin{array}{l}\text { One small single-blind clinical trial found that stool } \\
\text { frequency increased after the first-week treatment } \\
\text { with compared with placebo }(P<0.05) .{ }^{14}\end{array}$ & $\begin{array}{l}\text { Common side effects are flushing, diarrhea, } \\
\text { headache and anorexia. }\end{array}$ \\
\hline \multirow[t]{2}{*}{$\begin{array}{l}\text { Herbal } \\
\text { medications }\end{array}$} & Daikenchuto & $\begin{array}{l}\text { Appears to be safe and well tolerated. Promising in } \\
\text { animal studies but not widely studied in clinical } \\
\text { trials. }\end{array}$ & $\begin{array}{l}\text { Not been widely studied in clinical trials but in } \\
\text { small human trials, effects on colonic and } \\
\text { gastric transit were not statistically signifi- } \\
\text { cantly different from placebo. }{ }^{15,16}\end{array}$ \\
\hline & Hemp seed extract & $\begin{array}{l}\text { RCT with } 120 \mathrm{CC} \text { patients for } 8 \text { weeks found } \\
\text { responder rate for complete SBM of } 43.3 \% \text { with } \\
\mathrm{HSP} \text {, compared with } 8.3 \% \text { in placebo }(P< \\
0.05) .{ }^{17}\end{array}$ & More research is needed in this area. \\
\hline
\end{tabular}

CDCA, chenodeoxycholic acid; IBS-C, constipation-predominant irritable bowel syndrome; CC, chronic constipation; SBMs, spontaneous bowel movements; GC-C, guanylate cyclase-C; RCT, radomized controlled trial; HSP, hemp seed pill.

tion involving the presence of abdominal pain as a primary complaint in IBS-C but not in FC. However, the considerable symptom overlap between these 2 disorders has been highlighted in recent studies, ${ }^{18,19}$ and similar therapeutic strategies are often utilized. Wong et $\mathrm{al}^{18}$ examined the overlap between FC and IBS-C that would result if the requirement that no patient meeting criteria for IBS-C could also be diagnosed with FC was removed. The authors found that among 432 patients, $89.5 \%$ of IBC-C cases met criteria for FC, and $43.8 \%$ of FC patients fulfilled criteria for IBS-C. Furthermore, by 12 months, 1 in 3 patients with FC transitioned to IBS-C and one-third of IBS-C changed to FC. Thus, these entities are likely to be part of the same condition with patients located along a spectrum of pain severity modulated by serotonin signaling. ${ }^{19}$ Because of this overlap and transition between diagnoses, it follows that several drugs have been found to be effective for the treatment of symptoms re- lated to both IBS-C and FC.

\section{Current Therapies for Constipation- predominant Irritable Bowel Syndrome and Chronic Constipation}

Traditional IBS-C and CC therapies, such as fiber and laxatives, have tended to focus on the improvement of specific bowel complaints such as stool frequency and stool consistency. Recently, more specific agents, including lubiprostone and linaclotide, are being utilized.

Fiber (either dietary or supplementary) has been long recommended as first-line therapy for functional bowel disease symptoms despite the limited evidence surrounding its use. ${ }^{20}$ It is apparent from trials identified by systematic reviews that there is a relative paucity of high quality evidence to support this approach, 
especially for insoluble fiber. When fiber is recommended for functional bowel disease, use of a soluble supplement such as ispaghula/psyllium, is best supported by the available data. Even when used judiciously, fiber can exacerbate abdominal distension, flatulence, constipation and diarrhea.

Although stimulant laxatives such as sodium picosulfate and bisacodyl are routinely used in clinical practice for $\mathrm{CC}$, the evidence surrounding their efficacy has, until recently, been in somewhat short supply. In a recent randomized placebo controlled trial of 468 patients with CC, sodium picosulfate improved stool frequency over 4 weeks. ${ }^{21}$ The percentage of patients with an increase of 1 or more mean complete spontaneous bowel movements (CSBMs) per week compared to baseline was $65.5 \%$ vs. $32.3 \%$, respectively $(P<0.0001)$. Patients had a mean stool frequency of once daily after treatment with picosulfate, suggesting greater efficacy than the serotonin $\left(5-\mathrm{HT}_{4}\right)$ partial agonist te$\operatorname{gaserod}^{22}$ and the chloride channel activator lubiprostone, ${ }^{23}$ though these were not compared directly. A 2010 radomized controlled trial (RCT) examined the effect of bisacodyl on CC over 4 weeks in 368 patients. ${ }^{24}$ The mean difference in CSBMs/week between the treatment and placebo arm was $3.3(P<0.001)$.
Stimulant laxatives may be used as needed or more regularly if required as long-term use does not appear to damage the enteric nervous as previously thought. ${ }^{25,26}$

Finally, osmotic laxatives such as polyethylene glycol (PEG) 3350 are an established treatment for $\mathrm{CC}$ and are often recommended for IBS-C. The 2005 American College of Gastroenterology summary statement gave PEG a grade A recommendation for the treatment of $\mathrm{CC},{ }^{27}$ a recent meta-analyses found the number needed to treat (NNT) with osmotic laxatives to be 3 (95\% CI 2 to 4$){ }^{28}$ An RCT demonstrated PEG's safety and efficacy in 304 subjects, including elderly patients, over 6 months. ${ }^{29}$ Improvement was seen in $52 \%$ of PEG and $11 \%$ of placebo subjects $(P$ $<0.001)$. However, the impact of osmotic laxatives for IBS-C, particularly for the pain component of this condition, is less clear. A recent placebo controlled RCT in IBS-C found PEG to be effective in increasing bowel frequency (between group difference 1.56 spontaneous bowel movements [SBMs]/week, $P<0.0001$ ) but not severity of abdominal pain (between group difference $-0.04, P>0.05) .{ }^{30} \mathrm{~A}$ similar study in adolescents demonstrated an improvement in stool frequency with PEG but no impact on pain intensity. ${ }^{31}$

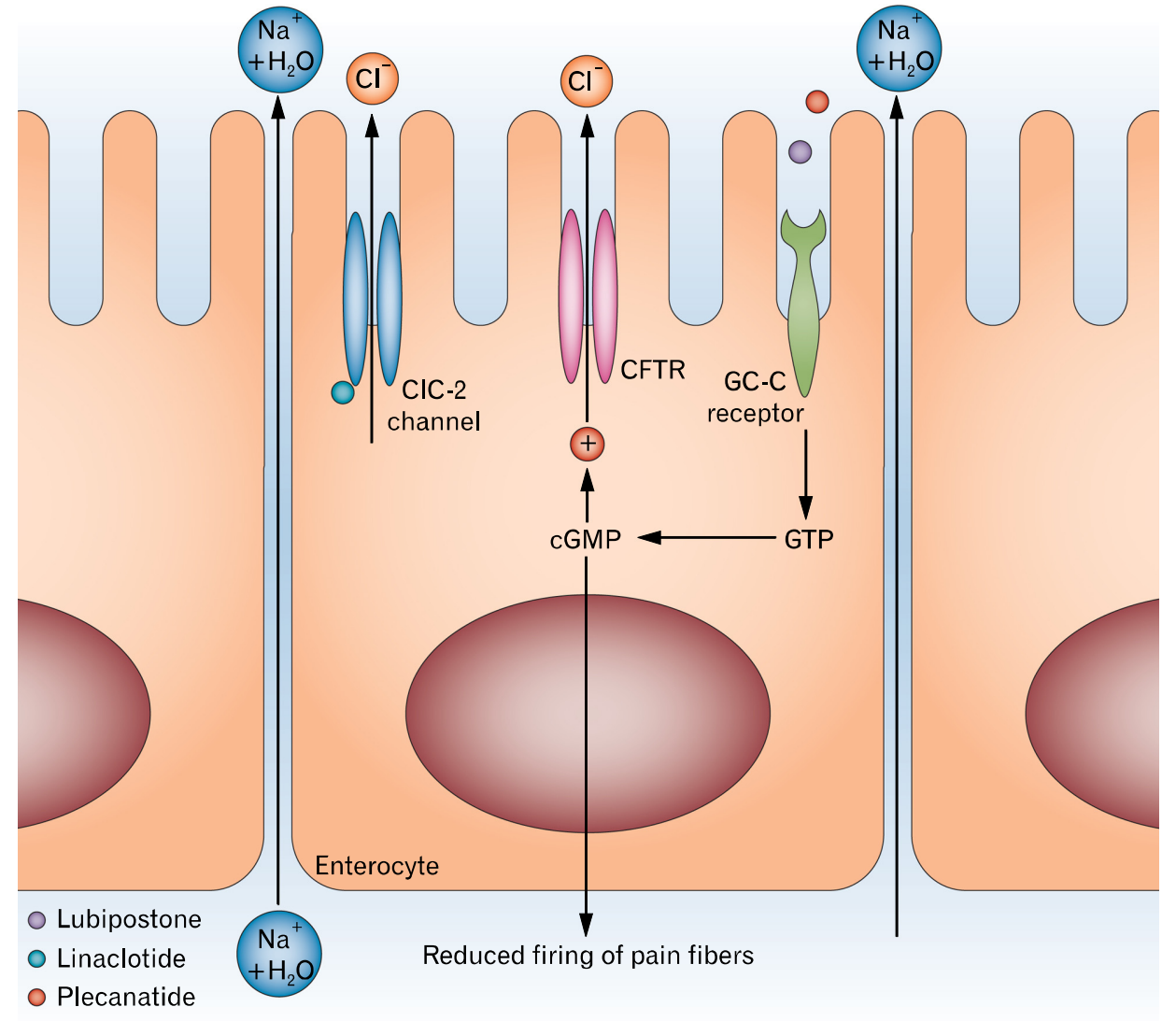

Figure 1. Chloride channel activation in the treatment of constipation. Reprinted from Menees et $\mathrm{al}^{32}$ with permission from Macmillan Publishers Ltd. ClC-2, type-2 chloride channel; CFTR, cystic fibrosis transmembrane regulator; GC-C, guanylate cyclase-C; GTP, guanosine triphosphate; cGMP, cyclic guanosine monophosphate. 


\section{Lubiprostone}

Lubiprostone is approved for IBS-C in women and for CC in adults. A prostone derived from prostaglandin E1, lubiprostone is a locally-acting, highly selective activator of type- 2 chloride channels and cystic fibrosis transmembrane conductance regulator chloride channels, located on the apical aspect enterocytes resulting in the passive paracellular movement of sodium and water (Fig. 1). ${ }^{32}$ The luminal distension by increased intestinal fluid promotes gastrointestinal (GI) tract motility which in turn increases the intestinal and colonic transit. ${ }^{33}$ Lubiprostone also enhances and stimulates contraction in colonic as well as gastric muscles through prostaglandin E receptors, suggesting direct effects on GI motility. ${ }^{34,35}$ This drug has been approved by the Food and Drug Administration (FDA) as a treatment for women and men with chronic constipation at a dose of $24 \mu \mathrm{g}$, twice daily, and for women with IBS-C at a dose of $8 \mu \mathrm{g}$, twice daily. Lubiprostone is contraindicated in mechanical GI obstruction and is FDA pregnancy category $\mathrm{C}$.

Lubiprostone has been consistently demonstrated to be superior to placebo for increasing the number of SBMs, improving stool consistency, reducing straining, bloating and overall constipation symptoms in several large, multicenter RCTs involving CC and IBS-C. ${ }^{23,36-40}$ One phase III trial in CC involved 242 patients (average age: 48 years; $89 \%$ female; $88 \%$ Caucasian) who received either lubiprostone $24 \mu \mathrm{g}$ twice daily or placebo with food for a period of 4 weeks with a primary efficacy end point of number of SBM at 1 week of treatment. ${ }^{23}$ Those receiving lubiprostone experienced a significant increase in SBMs compared with placebo at week 1 (5.7 vs. $3.5 ; P=0.0001)$, an improvement that was seen throughout the 4 week study. Benefits in patients with opioid-induced constipation have also been reported. $^{41,42}$

Drossman et $\mathrm{al}^{38}$ evaluated over 1100 IBS-C patients in a placebo-controlled RCT, demonstrating that lubiprostone $8 \mu \mathrm{g}$ twice daily resulted in significantly higher overall response compared to placebo $(17.9 \%$ vs. $10.1 \%, P=0.001)$ over 12 weeks of treatment. An extension study of this trial determined lubiprostone to be safe and well tolerated over 52 weeks, with the most common adverse effects of diarrhea (11\%), nausea (11\%), urinary tract infection (9\%) and sinusitis (9\%). ${ }^{41}$ Side effects seem to be dose dependent; with considerably more gastrointestinal adverse events (specifically nausea at 44\%) observed at higher doses compared to the $24 \mu \mathrm{g}$ once daily regimen (17\%). Frequency of administration was not found to affect therapeutic outcomes. ${ }^{39}$
Nausea appears to be less prevalent in males (8\%) and the elderly $(19 \%) .{ }^{43,44}$ Outside of reducing the dose of lubiprostone, treatment-associated nausea can also be reduced by dosing with food.

\section{Linaclotide}

Linaclotide is an orally administered minimally absorbed 14-amino acid peptide that acts peripherally on the guanylate cyclase-C (GC-C) receptor located on the luminal surface of intestinal epithelial cells. Activation of the GC-C receptor leads to the production of intracellular cyclic guanosine monophosphate (cGMP) which activates the cystic fibrosis transmembrane regulator resulting in active secretion of chloride into the intestinal lumen (Fig. 1). ${ }^{32}$ As a consequence of this active chloride secretion, there is passive paracellular movement of sodium and water. ${ }^{45} \mathrm{In}$ addition, extracellular cGMP reduces firing of visceral afferent neurons in animal models, suggesting potential benefits of linaclotide for abdominal pain. ${ }^{46}$ In animal models, linaclotide activates $\mathrm{GC}-\mathrm{C}$ expressed on mucosal epithelial cells, resulting in the production and release of cGMP, inhibiting nociceptors, and thereby reducing nociception. ${ }^{47-49}$ The activation of GC-C may attenuate the stretch response, dampen stretch-sensitive afferents and normalize afferent sensitization. ${ }^{48,49}$

The FDA has approved linaclotide for IBS-C at a dose of $290 \mu \mathrm{g}$ daily and for chronic idiopathic constipation (CIC) at a dose of $145 \mu \mathrm{g}$ daily. Linaclotide received its first global approval in August 2012 for the treatment of IBS-C and CIC in the US and in September 2013 for approval for the treatment of IBS-C in Europe. ${ }^{50}$ It is recommended to take linaclotide on an empty stomach at least 30 minutes prior to the first meal of the day, and linaclotide is FDA pregnancy category $\mathrm{C}$.

Two randomized, multicenter, double-blind, dual-dose, placebo-controlled trials of linaclotide have been conducted in patients with CC involving over 1,276 patients. ${ }^{51}$ Patients received placebo or linaclotide, $145 \mu \mathrm{g}$ or $290 \mu \mathrm{g}$, once daily for 12 weeks. The primary efficacy end point was three or more CSBMs per week and an increase of one or more CSBMs from baseline during at least 9 of the 12 weeks. For both trials, the primary end point was reached by $21.2 \%$ and $16.0 \%$ of the patients who received $145 \mu \mathrm{g}$ of linaclotide and by $19.4 \%$ and $21.3 \%$ of the patients who received $290 \mu \mathrm{g}$ of linaclotide, compared with $3.3 \%$ and $6.0 \%$ of those who received placebo $(P<0.01$ for all comparisons of linaclotide with placebo). Improvements in all secondary end points (including stool frequency, stool consistency, severity of straining, abdominal discomfort, bloating and constipation severity) were significantly greater in both linaclotide 
groups than in the placebo groups. The incidence of adverse events was similar among all study groups, with the exception of diarrhea, which led to discontinuation of treatment in $4.2 \%$ of patients in both linaclotide groups.

Linaclotide has also been studied in patients with IBS-C. ${ }^{52,53}$ A phase III, 6 month, double-blind, placebo-controlled study found that linaclotide $290 \mu \mathrm{g}$ daily significantly improved abdominal and bowel symptoms associated with IBS-C in 804 patients. ${ }^{53}$ One of the prespecified primary end points included the FDA's recommended composite end point which required improvement of $\geq 30 \%$ from baseline in average daily worst abdominal pain score as well as an increase of $\geq 1$ CSBM from baseline, both in the same week for $\geq 6 / 12$ weeks. Linaclotide resulted in a response rate of $33.7 \%$ vs. $13.9 \%$ for placebo-treated patients $(P<0.0001)(\mathrm{NNT}, 5.1 ; 95 \% \mathrm{CI}, 3.9-7.1)$. When breaking down the data to its component symptoms, $48.9 \%$ of linaclotide-treated patients vs. $34.5 \%$ of placebo-treated patients reported $\mathrm{a} \geq 30 \%$ reduction in average daily worst abdominal pain score (NNT, 7.0; $95 \% \mathrm{CI}, 4.7-13.1$ ), and $47.6 \%$ of linaclotide-treated patients, vs. $22.6 \%$ of placebo patients (NNT, 4.0; $95 \% \mathrm{CI}, 3.2-5.4$ ) reported an increase of $\geq 1$ CSBM per week from baseline. While maximum improvements in stool frequency occurred within the first 1-2 weeks, maximum benefits for abdominal pain were not achieved until 8-12 weeks after initiation of linaclotide. Diarrhea was reported more commonly with linaclotide vs. placebo (20.0\% vs. $2.5 \%$ ). Of the 79 patients who developed diarrhea, it was generally rated as mild to moderate in severity and usually occurred (76\%) within the first 4 weeks of initiating linaclotide. Diarrhea resulted in study discontinuation in $4.5 \%$ of linaclotide patients vs. $0.2 \%$ of placebo patients. Other than diarrhea, the incidence of adverse events was similar between treatment groups.

A number of additional analyses of data from phase III IBS-C trials have recently been reported. In a prespecified analysis using the suggested primary endpoint from the European Medicines Agency, Quigley and colleagues ${ }^{54}$ reported a significantly greater proportion of linaclotide-treated vs. placebo-treated patients were 12 -week "degree-of-relief” responders (39.4\% vs. $16.6 \%$; $P<$ 0.0001 ) (responder: symptoms "considerably" or "completely" relieved for $\geq 6$ weeks). In another analysis, it was found that $86 \%$ of global IBS symptom responders at 4 weeks reported durable relief at 12 weeks. Further, more than a third of nonresponders at 4 weeks became responders at 12 weeks suggesting that a treatment trial of greater than 4 weeks may be necessary in some patients. ${ }^{55}$

\section{Emerging Therapies for Constipation- predominant Irritable Bowel Syndrome and Chronic Constipation}

\section{Bile Acid Modulators (Chenodeoxycholic Acid and Elobixibat)}

Ileal bile acid transporters located in the terminal ileum normally absorb $97 \%$ of luminal bile acids. Bile acids which are not absorbed in the terminal ileum spill over into the proximal colon, where they are deconjugated and dehydroxylated by colonic microbiota to produce secondary bile acids such as deoxycholic acid, which induce colonic secretion. ${ }^{56}$ There is also considerable evidence that bile acids can modify colonic motility through direct effects on colonic neuromuscular activity independently of secre-

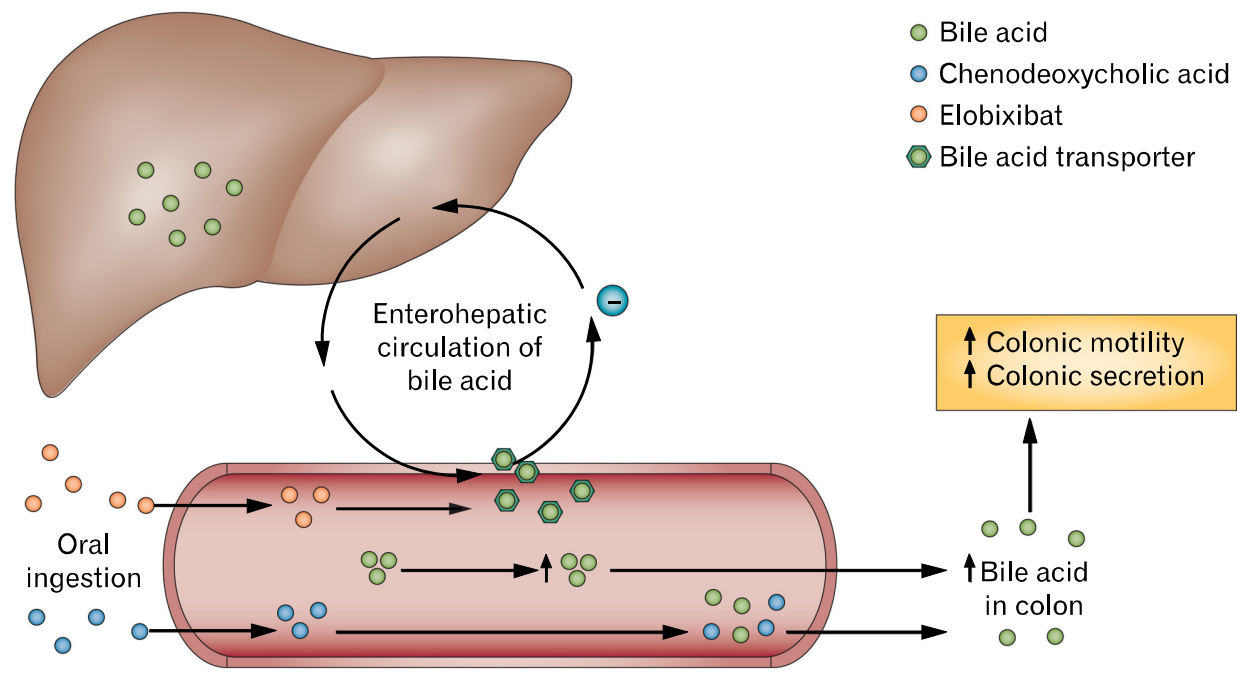

Figure 2. The use of bile acids to treat constipation. Normally, bile acids are removed from the ileum via transporters to the liver as part of enterohepatic circulation, leading to reduced concentrations of bile acid reaching the colon and decreased colonic motility. Elobixibat inhibits the uptake of bile acids in the terminal ileum, which increases luminal concentration and improves colonic motility. Chenodeoxycholic acid is a bile acid analogue that increases the concentration of bile acid in the gut and promotes colonic motility. Modified from Menees et $\mathrm{al}^{32}$ with permission from Macmillan Publishers Ltd. 
tory effects. ${ }^{57}$ Recently, a study showed that measurements of individual urinary bile acids were associated with stool characteristics in patients with IBS; these effects were independent of the effects of colonic transit. ${ }^{58}$ A similar study demonstrated that serum and stool levels of bile acids were increased in diarrhea-predominant IBS patients compared to healthy controls. ${ }^{59}$ Thus, the modulation of luminal bile acid concentrations represents a novel treatment strategy for patients with bowel disturbances. Specifically, the supplementation of specific bile acid analogues or use of drugs that inhibit ileal bile acid reabsorption may be helpful in treating constipation or IBS-C (Fig. 2).

\section{Sodium chenodeoxycholate}

Bile acids such as chenodeoxycholic acid, previously used for dissolution of gallstones, are known to elicit diarrhea at higher doses in healthy controls and constipated patients. ${ }^{60-63}$ Rao et $\mathrm{al}^{5}$ showed in a double-blind placebo-controlled study that sodium chenodeoxycholate (CDC), a primary bile acid, accelerated colonic transit and improved bowel function in 36 female patients with IBS-C. Looser stool consistency $(P=0.003)$, increased stool frequency $(P=0.018)$ and greater ease of stool passage $(P$ $=0.024)$ were noted with CDC compared with placebo. Unfortunately, over $40 \%$ of patients treated with CDC reported lower abdominal cramping/pain $(P=0.010)$. Whether this side effects could be mitigated while maintaining clinical benefits with a lower dose remains to be determined. Interestingly, the authors found that genetic variations in the proteins involved in the feedback inhibitory pathway of bile acid synthesis may influence the effects of CDC on colonic transit. Further studies with CDC and other primary bile acids in patients with chronic constipation and IBS-C will be of interest.

\section{Elobixibat (A3309)}

An alternative strategy to providing supplemental bile acids is to inhibit reabsorption of native bile acids in the terminal ileum. Elobixibat (formerly A3309) is a first-in-class selective, minimally absorbed ileal bile acid transporter inhibitor, reducing the active ileal reabsorption of bile acids, resulting in an increased concentration of bile acids entering the colon, which stimulates colonic motility and secretion. Pharmacodynamic studies with elobixibat have demonstrated acceleration of colonic transit, increased stool frequency, improved stool consistency and relief of constipation-related symptoms in CIC patients. ${ }^{64}$ Elobixibat has been tested in phase II trials involving patients with CIC; the 3 studies published to date report similar results regarding the effi- cacy and safety of elobixibat compared with placebo, in improving the number of SBMs, stool consistency and in decreasing straining. ${ }^{6-8}$ There was no consistent amelioration of abdominal pain or bloating, except at the $15 \mathrm{mg}$ daily dose, acknowledging that these studies were conducted in patients with CIC. ${ }^{7,8}$ Studies in patients with IBS-C (where abdominal pain or cramping is a primary complaint) have not yet been conducted. Further evaluation of elobixibat in phase 3 clinical trials to confirm the most appropriate and well-tolerated treatment dose and the effects of long-term administration are ongoing.

\section{Guanylate Cyclase-C Receptor Agonists (Plecanatide)}

\section{Plecanatide (SP-304)}

Similar to lincaclotide, plecanatide, an analogue of uroguanylin, activates the GC-C receptor found on GI mucosal epithelial cells, leading to intracellular secretory and extracellular anti-nociceptive effects via a cGMP mediated second messenger pathway (Fig. 1). ${ }^{32,65,66}$ Plecanatide is a luminally acting drug with little measurable systemic exposure which is being investigated as a treatment for CC and IBS-C. ${ }^{9}$ Shailubhai et al ${ }^{9}$ completed a phase IIa trial, demonstrating that plecanatide was safe and well-tolerated in single doses up to $48.6 \mathrm{mg}$ and that dosages of $0.3,1.0,3.0$ and $9.0 \mathrm{mg}$ once daily for 14 days improved stool frequency, straining and abdominal discomfort in 84 patients with CC. A phase III trial evaluating plecanatide $3 \mathrm{mg}$ per day vs. placebo for 12 weeks in $951 \mathrm{CC}$ patients reported that $21.5 \%$ vs. $11.5 \%(P=0.003)$ were primary endpoint responders $(\geq 3$ CSBMs/week and increase of $\geq 1 \mathrm{CSBM} /$ week for $\geq 9 / 12$ weeks). ${ }^{67}$ Diarrhea was reported with plecanatide more often than placebo (9.7\% vs. $1.3 \%)$ though discontinuation was infrequent in both groups (plecanatide $3.0 \%$ vs. placebo $0.4 \%$ ). Studies evaluating the efficacy of plecanatide in patients with IBS-C have yet to be reported.

\section{Serotonin Receptor Modulators}

\section{The 5-HT 4 receptor agonists (prucalopride and mosa- pride)}

Prucalopride. Prucalopride is a selective $5-\mathrm{HT}_{4}$ receptor agonist with prokinetic activity that is known to accelerate colonic transit and improve constipation related complaints. ${ }^{68}$ Prucalopride stimulates high-amplitude propagated contractions and increases segmental contractions, which are likely to be the under- 
lying mechanisms of its effects on bowel habits. ${ }^{69}$

Three trials (which assessed 620, 641 and 713 patients, respectively) examining the use of prucalopride in CC demonstrated a significant increase in the proportion of patients achieving at least 3 SBMs per week compared with placebo. ${ }^{10-12}$ Response rates ranged from $19.5 \%$ to $31 \%$ with $2 \mathrm{mg}$ prucalopride, $24 \%$ to $28 \%$ with $4 \mathrm{mg}$ prucalopride and $9.6 \%$ to $12 \%$ with placebo over 12 weeks. Over $85 \%$ of study subjects were women. Improvements in disease-specific quality of life were maintained during open-label treatment for up to 18 months. ${ }^{70}$ Most frequent adverse events resulting in discontinuation were GI events (nausea, abdominal pain and diarrhea [3.3\%]) and headache $(1.0 \%)$. The serious cardiac adverse events (palpitations, myocardial infarction, ventricular fibrillation, torsades de pointes and sudden death) and medication interactions that led to the withdrawal of the less selective serotonergic agonists cisapride and tegaserod have not been observed with prucalopride. ${ }^{71}$

The comparative effectiveness of prucalopride versus the more commonly recommended osmotic agent PEG was recently evaluated in a single center RCT from Romania. ${ }^{72}$ Two hundred and forty CIC patients received either PEG 3350 and electrolytes (26 g) or prucalopride (1-2 mg) for 28 days. For the primary endpoint (proportion of patients having $\geq 3 \mathrm{CSBM}$ during the last treatment week), the treatments were non-inferior in a modified intention-to-treat analysis. Surprisingly, PEG led to significant benefits over prucalopride for most of the prespecified secondary variables (bowel frequency, stool consistency, time to next CSBM, perception of straining and completeness of defecation). No differences in tolerability were observed.

As yet, limited data exist on the impact of prucalopride on motility disorders affecting other parts of the GI tract such as gastroparesis, chronic intestinal pseudo-obstruction, and, most importantly, IBS-C. It is currently approved for use in Europe and Canada, but has not been approved by the FDA for use in the United States. It is indicated for women with CC in whom laxatives have failed to provide adequate relief. The recommended dosage in adults is $2 \mathrm{mg}$ administered orally once daily.

Mosapride. The 5- $\mathrm{HT}_{4}$ receptor agonist has documented stimulatory effects on gastric and colonic motility. Unlike cisapride, mosapride does not bind to $\mathrm{K}^{+}$channels or $\mathrm{D}_{2}$ dopaminergic receptors. Mosapride was primarily developed for upper GI tract conditions, such as functional dyspepsia, gastro- esophageal reflux disease, and nausea and vomiting and is available for these indications in several countries in Central and South America, Europe and the Far East. However, the effect of mosapride on colonic function has not been well investigated. Kanazawa et $\mathrm{al}^{73}$ investigated whether mosapride altered rectosigmoid motility and perception in patients with IBS. In 17 IBS-C patients, mosapride increased rectosigmoid tone $(P<$ $0.01)$ and contractions $(P<0.05)$ more than placebo. ${ }^{73}$ Furthermore, Nakamura et $\mathrm{al}^{13}$ found that after 4 weeks of mosapride administration, the mean scores of evaluated symptoms all improved. Gastric transit time was not significantly changed, but small bowel transit time was significantly shortened post-administration $(P=0.02)$. Mosapride is generally well tolerated. Side effects include diarrhea, dry mouth and headache. ${ }^{74}$ One small underpowered placebo controlled trial was no different than placebo in the relief of IBS-C symptoms. ${ }^{75}$ No published studies have adequately addressed the role of mosapride in the management of IBS-C or CC.

\section{Sodium Reuptake Inhibitors}

RDX5791 is a first-in-class potent and selective inhibitor of $\mathrm{Na}^{+} / \mathrm{H}^{+}$antiport protein, a sodium transporter on the surface of the intestinal epithelia. The intestinal $\mathrm{Na}^{+} / \mathrm{H}^{+}$antiport protein plays a key role in the uptake of sodium, and thus water, from the intestinal lumen. Animal studies have demonstrated a dose related increase in in fecal water content and transit rate with minimal systemic exposure. ${ }^{76}$ It is currently in phase II trials for IBS-C.

\section{Partial $5-\mathrm{HT}_{3}$ Receptor Agonists}

\section{Pumosetrag (MKC-733)}

Pumosetrag, a $5-\mathrm{HT}_{3}$ receptor partial agonist, is a novel enteroprokinetic compound which stimulates small bowel transit dose dependently. ${ }^{77}$ A single-blind study showed that pumosetrag $0.5 \mathrm{mg}$ improved bowel motility in 14 patients with CC. In the low bowel motility group, both geometric mean and percent elimination increased after treatment $(P<0.05)$. Stool frequency increased after the first-week treatment with MKC-733 compared with placebo $(P<0.05) .{ }^{14}$ Common side effects are flushing, diarrhea, headache and anorexia. ${ }^{74}$ 


\section{Herbal Medications (Daikenchuto and Hemp Seed Extract)}

\section{Daikenchuto (TU-100 and DKT)}

Daikenchuto, a Japanese herbal medicine, which consists of an extract powder from dried Sichuan pepper, processed ginger, ginseng and maltose powder, has been used for the treatment of paralytic ileus and radiation-induced enteritis due to its possible prokinetic effects. ${ }^{78-81}$ A pharmaceutical grade version of daikenchuto, TU-100, has not been widely studied in clinical trials but appears to be safe and well tolerated. TU-100 demonstrated prokinetic effects on colonic transit in animal studies but in subsequent human trials, effects on colonic and gastric transit were not statistically significantly different from placebo. ${ }^{15,16}$

\section{Hemp seed extract}

Hemp seed extract is a popular Chinese herbal medicine which is often used to treat FC. Cheng et $\mathrm{al}^{17}$ evaluated 120 patients with FC for 8 weeks. For an endpoint of a mean increase of $\mathrm{CSBM} \geq 1$ /week compared with baseline, hemp seed pill $7.5 \mathrm{~g}$ twice daily produced a response in $43.3 \%$, compared to $8.3 \%$ with placebo $(P<0.05)$. Additionally, a sustained increase in the frequency of CSBMs was observed during the post-treatment period in the hemp seed pill group (30\%) compared to placebo (15\%) $(P<0.05)$. Those who received hemp seed also experienced improvements in constipation severity, straining, and use of rescue therapy when compared with placebo. No serious adverse events were reported. Further research to evaluate this potentially effective therapy is warranted.

\section{Alternative Therapies}

\section{Probiotics}

Probiotics are known to be generally safe and may offer benefits to patients with functional GI disorders by improving intestinal barrier function, altering epithelial surface glycosylation pattern, increasing mucus production, secreting antimicrobial peptides, modulating the immune system and altering fermentation. ${ }^{82}$ The role of probiotics in IBS remains unclear, although Bifidobacterium infantis has demonstrated positive effects in RCTs. In a systematic review by Brenner et $\mathrm{al}^{83}$ which included 16 RCTs, B. infantis 35624 was found to reduce intestinal inflammation and showed significant improvement in the compo- site score for abdominal pain/discomfort, bloating/distention and/or bowel movement difficulty compared with placebo $(P<$ $0.05)$ in 2 RCTs. ${ }^{83-85}$ No other probiotics showed significant improvement in IBS symptoms in a high quality RCT. ${ }^{75}$ To date, there is little high quality evidence to support the efficacy of single strain Lactobacillus containing probiotics. ${ }^{82,86}$ Clearly, further work in this area will be required to determine the magnitude of benefit and most effective strain/species in IBS.

\section{Diet}

Prunes. Dried plums (prunes) not only contain fiber but also sorbitol and fructans, non-absorbable carbohydrates that, when fermented by colonic bacteria, create an osmotic load that can dramatically alter stool frequency and consistency. In an 8-week single-blind, randomized study with 40 constipated subjects, the number of CSBMs per week and stool consistency scores improved significantly $(P<0.05)$ with prunes when compared to psyllium. Straining and global constipation symptoms did not differ significantly between treatments. ${ }^{87}$

Kiwi. In a recent study from Asia, 41 IBS-C patients and 16 healthy adults consumed 2 Hayward green kiwifruits per day for 4 weeks. Another 13 IBS-C patients served as controls. IBS-C patients that consumed kiwi fruit had a significantly faster colonic transit time than controls $(P=0.026)$. The IBS-C kiwifruit group also reported increases in defecation frequency and improvements in bowel function. ${ }^{88}$

\section{Conclusions}

Chronic FC and IBS-C are common problems faced by both primary care physicians and gastroenterologists. The Rome III criteria distinguish between these 2 disorders mainly through the presence of abdominal pain or discomfort as a primary and clinically significant complaint in IBS-C but not chronic FC. From a regulatory standpoint, these conditions are treated as separate entities but in clinical practice, the symptoms of IBS-C and chronic FC overlap significantly and oftentimes, their distinction is quite arbitrary. To a certain extent, this suggestion is supported by the current industry model of sequential or even parallel development of novel drugs for chronic FC and IBS-C. Only time will tell if the upcoming Rome IV criteria will uphold the current separation between chronic FC and IBS-C or suggest a paradigm shift which acknowledges the undeniable overlap between these conditions. What is clear is that the current symptom-based diagnostic criteria invite pathophysiological heterogeneity and ensure that 
"effective" treatments are likely to offer only marginal gains over placebo. Clinicians often take these modest therapeutic gains over placebo to mean that drugs are ineffective. On the contrary, if one considers drugs which target a specific pathophysiologic pathway (for example: serotonin, chloride channels, guanylate cyclase and colonic bile acid concentrations etc.) as biological probes, results from methodologically rigorous $\mathrm{RCT}$ s provide insight into the proportion of patients whose symptoms are likely to be related to that pathophysiological abnormality. Future research should focus on not only the development of novel treatments but also biomarkers which provide insights into pathogenesis and treatment response.

\section{References}

1. Saito YA, Schoenfeld P, Locke GR 3rd. The epidemiology of irritable bowel syndrome in North America: a systematic review. Am J Gastroenterol 2002;97:1910-1915.

2. Higgins PD, Johanson JF. Epidemiology of constipation in North America: a systematic review. Am J Gastroenterol 2004;99:750-759.

3. Lovell RM, Ford AC. Global prevalence of and risk factors for irritable bowel syndrome: a meta-analysis. Clin Gastroenterol Hepatol 2012;10:712-721, e4.

4. Longstreth GF, Thompson WG, Chey WD, Houghton LA, Mearin F, Spiller RC. Functional bowel disorders. Gastroenterology 2006;130:1480-1491.

5. Rao AS, Wong BS, Camilleri M, et al. Chenodeoxycholate in females with irritable bowel syndrome-constipation: a pharmacodynamic and pharmacogenetic analysis. Gastroenterology 2010;139: 1549-1558, e1.

6. Simren M, Bajor A, Gillberg PG, Rudling M, Abrahamsson H. Randomised clinical trial: the ileal bile acid transporter inhibitor A3309 vs. placebo in patients with chronic idiopathic constipation - a double-blind study. Aliment Pharmacol Ther 2011;34:41-50.

7. Wong BS, Camilleri M, McKinzie S, Burton D, Graffner H, Zinsmeister AR. Effects of A3309, an ileal bile acid transporter inhibitor, on colonic transit and symptoms in females with functional constipation. Am J Gastroenterol 2011;106:2154-2164.

8. Chey WD, Camilleri M, Chang L, Rikner L, Graffner H. A randomized placebo-controlled phase IIb trial of A3309, a bile acid transporter inhibitor, for chronic idiopathic constipation. Am J Gastroenterol 2011;106:1803-1812.

9. Shailubhai K, Comiskey S, Foss JA, et al. Plecanatide, an oral guanylate cyclase $\mathrm{C}$ agonist acting locally in the gastrointestinal tract, is safe and well-tolerated in single doses. Dig Dis Sci 2013;58:2580-2586.

10. Tack J, van Outryve M, Beyens G, Kerstens R, Vandeplassche L. Prucalopride (Resolor) in the treatment of severe chronic constipation in patients dissatisfied with laxatives. Gut 2009;58:357-365.

11. Camilleri M, Kerstens R, Rykx A, Vandeplassche L. A placebo-controlled trial of prucalopride for severe chronic constipation. N Engl J Med 2008;358:2344-254.

12. Quigley EM, Vandeplassche L, Kerstens R, Ausma J. Clinical trial: the efficacy, impact on quality of life, and safety and tolerability of prucalopride in severe chronic constipation - a 12-week, randomized, double-blind, placebo-controlled study. Aliment Pharmacol Ther 2009;29:315-328.

13. Nakamura M, Ohmiya N, Miyahara R, et al. Are symptomatic changes in irritable bowel syndrome correlated with the capsule endoscopy transit time? A pilot study using the $5-\mathrm{HT}_{4}$ receptor agonist mosapride. Hepatogastroenterology 2011;58:453-458.

14. Fujita T, Yokota S, Sawada M, Majima M, Ohtani Y, Kumagai Y. Effect of MKC-733, a 5- $\mathrm{HT}_{3}$ receptor partial agonist, on bowel motility and symptoms in subjects with constipation: an exploratory study. J Clin Pharm Ther 2005;30:611-622.

15. Manabe N, Camilleri M, Rao A, et al. Effect of daikenchuto (TU100) on gastrointestinal and colonic transit in humans. Am J Physiol Gastrointest Liver Physiol 2010;298:G970-G975.

16. Iturrino J, Camilleri M, Wong BS, Linker Nord SJ, Burton D, Zinsmeister AR. Randomised clinical trial: the effects of daikenchuto, TU-100, on gastrointestinal and colonic transit, anorectal and bowel function in female patients with functional constipation. Aliment Pharmacol Ther 2013;37:776-785.

17. Cheng CW, Bian ZX, Zhu LX, Wu JC, Sung JJ. Efficacy of a Chinese herbal proprietary medicine (Hemp Seed Pill) for functional constipation. Am J Gastroenterol 2011;106:120-129.

18. Wong RK, Palsson OS, Turner MJ, et al. Inability of the Rome III criteria to distinguish functional constipation from constipation-subtype irritable bowel syndrome. Am J Gastroenterol 2010;105:22282234.

19. Shekhar C, Monaghan PJ, Morris J, et al. Rome III functional constipation and irritable bowel syndrome with constipation are similar disorders within a spectrum of sensitization, regulated by serotonin. Gastroenterology 2013;145:749-757.

20. Eswaran S, Muir J, Chey WD. Fiber and functional gastrointestinal disorders. Am J Gastroenterol 2013;108:718-727.

21. Mueller-Lissner S, Kamm MA, Wald A, et al. Multicenter, 4-week, double-blind, randomized, placebo-controlled trial of sodium picosulfate in patients with chronic constipation. Am J Gastroenterol 2010;105:897-903.

22. Kamm MA, Muller-Lissner S, Talley NJ, et al. Tegaserod for the treatment of chronic constipation: a randomized, double-blind, placebo-controlled multinational study. Am J Gastroenterol 2005;100: 362-372.

23. Johanson JF, Morton D, Geenen J, Ueno R. Multicenter, 4-week, double-blind, randomized, placebo-controlled trial of lubiprostone, a locally-acting type-2 chloride channel activator, in patients with chronic constipation. Am J Gastroenterol 2008;103:170-177.

24. Kamm MA, Müller-Lissner SA, Wald A, et al. S1321 stimulant laxatives are effective in chronic constipation: multi-center, 4-week, double-blind, randomized, placebo-controlled trial of bisacodyl. Gastroenterology 2010;138(suppl 1):S-228.

25. Dufour P, Gendre P. Ultrastructure of mouse intestinal mucosa and changes observed after long term anthraquinone administration. Gut 1984;25:1358-1363.

26. Kiernan JA, Heinicke EA. Sennosides do not kill myenteric neurons in the colon of the rat or mouse. Neuroscience 1989;30:837-842.

27. American College of Gastroenterology Chronic Constipation Task Force. An evidence-based approach to the management of chronic 
constipation in North America. Am J Gastroenterol 2005;100(suppl 1):S1-S4

28. Ford AC, Suares NC. Effect of laxatives and pharmacological therapies in chronic idiopathic constipation: systematic review and meta-analysis. Gut 2011;60:209-218.

29. Dipalma JA, Cleveland MV, McGowan J, Herrera JL. A randomized, multicenter, placebo-controlled trial of polyethylene glycol laxative for chronic treatment of chronic constipation. Am J Gastroenterol 2007;102:1436-1441.

30. Chapman RW, Stanghellini V, Geraint M, Halphen M. Randomized clinical trial: macrogol/PEG 3350 plus electrolytes for treatment of patients with constipation associated with irritable bowel syndrome. Am J Gastroenterol 2013;108:1508-1515.

31. Khoshoo V, Armstead C, Landry L. Effect of a laxative with and without tegaserod in adolescents with constipation predominant irritable bowel syndrome. Aliment Pharmacol Ther 2006;23:191-196.

32. Menees S, Saad R, Chey WD. Agents that act luminally to treat diarrhoea and constipation. Nat Rev Gastroenterol Hepatol 2012;9:661674.

33. Jun JY. Role of lubiprostone on gastrointestinal motility. J Neurogastroenterol Motil 2013;19:277-278.

34. Chan WW, Mashimo H. Lubiprostone increases small intestinal smooth muscle contractions through a prostaglandin E receptor 1 (EP1)-mediated pathway. J Neurogastroenterol Motil 2013;19:312318.

35. Bassil AK, Borman RA, Jarvie EM, et al. Activation of prostaglandin EP receptors by lubiprostone in rat and human stomach and colon. Br J Pharmacol 2008;154:126-135.

36. Fukudo S, Hongo M, Kaneko H, Ueno R. Efficacy and safety of oral lubiprostone in constipated patients with or without irritable bowel syndrome: a randomized, placebo-controlled and dose-finding study. Neurogastroenterol Motil 2011;23:544, e205.

37. Barish CF, Drossman D, Johanson JF, Ueno R. Efficacy and safety of lubiprostone in patients with chronic constipation. Dig Dis Sci 2010;55:1090-1097.

38. Drossman DA, Chey WD, Johanson JF, et al. Clinical trial: lubiprostone in patients with constipation-associated irritable bowel syndrome - results of two randomized, placebo-controlled studies. Aliment Pharmacol Ther 2009;29:329-341.

39. Johanson JF, Ueno R. Lubiprostone, a locally acting chloride channel activator, in adult patients with chronic constipation: a double-blind, placebo-controlled, dose-ranging study to evaluate efficacy and safety. Aliment Pharmacol Ther 2007;25:1351-1361.

40. Chey WD, Drossman DA, Johanson JF, Scott C, Panas RM, Ueno R. Safety and patient outcomes with lubiprostone for up to 52 weeks in patients with irritable bowel syndrome with constipation. Aliment Pharmacol Ther 2012;35:587-599.

41. Cryer BL, Katz S, Vallejo R. A phase 3, randomized, double-blind, placebo-controlled clinical trial of lubiprostone for the treatment of opioid-induced bowel dysfunction in patients with chronic, non-cancer pain. Gastroenterology 2010;138(suppl 1):S-129.

42. Mazen Jamal M, Mareya SM, Woldegeorgis F, Joswick RT, Joswick RU. Lubiprostone significantly improves treatment response in non-methadone opioid-induced bowel dysfunction patients with chronic, non-cancer pain: results from a phase 3, randomized, double-blind, placebo-controlled clinical trial. Gastroenterology 2012; 142(suppl 1):S144-S145.

43. Ueno R, Wahle A, Rivera E. Pooled analysis of the most frequent adverse events associated with the use of lubiprostone. Am J Gastroenterol 2006;101(suppl 2):S489.

44. Saad R, Chey WD. Lubiprostone for chronic idiopathic constipation and irritable bowel syndrome with constipation. Expert Rev Gastroenterol Hepatol 2008;2:497-508.

45. Bryant AP, Busby RW, Bartolini WP, et al. Linaclotide is a potent and selective guanylate cyclase $\mathrm{C}$ agonist that elicits pharmacological effects locally in the gastrointestinal tract. Life Sci 2010;86:760-765.

46. Eutamene H, Bradesi S, Larauche M, et al. Guanylate cyclase C-mediated antinociceptive effects of linaclotide in rodent models of visceral pain. Neurogastroenterol Motil 2010;22:312, e84.

47. Castro J, Harrington AM, Hughes PA, et al. Linaclotide inhibits colonic nociceptors and relieves abdominal pain via guanylate cyclase-C and extracellular cyclic GMP. Gastroenterology 2013;145:13341346, e1-e11.

48. Feng B, Kiyatkin ME, La JH, et al. Activation of guanylate cyclase-C attenuates stretch responses and sensitization of mouse colorectal afferents. J Neurosci 2013;33:9831-989.

49. Silos-Santiago I, Hannig G, Eutamene H, et al. Gastrointestinal pain: unraveling a novel endogenous pathway through uroguanylin/ guanylate cyclase-C/cGMP activation. Pain 2013;154:1820-1830.

50. McWilliams V, Whiteside G, McKeage K. Linaclotide: first global approval. Drugs 2012;72:2167-2175.

51. Lembo AJ, Schneier HA, Shiff SJ, et al. Two randomized trials of linaclotide for chronic constipation. N Engl J Med 2011;365:527-536.

52. Rao S, Lembo AJ, Shiff SJ, et al. A 12-week, randomized, controlled trial with a 4-week randomized withdrawal period to evaluate the efficacy and safety of linaclotide in irritable bowel syndrome with constipation. Am J Gastroenterol 2012;107:1714-1724.

53. Chey WD, Lembo AJ, Lavins BJ, et al. Linaclotide for irritable bowel syndrome with constipation: a 26-week, randomized, double-blind, placebo-controlled trial to evaluate efficacy and safety. Am J Gastroenterol 2012;107:1702-1712.

54. Quigley EM, Tack J, Chey WD, et al. Randomised clinical trials: linaclotide phase 3 studies in IBS-C - a prespecified further analysis based on European Medicines Agency-specified endpoints. Aliment Pharmacol Ther 2013;37:49-61.

55. Chey WD, Lavins BJ, Shiff SJ, et al. Determining the minimum duration for initial treatment with linaclotide in IBS-C patients: results from pooled phase 3 trials. Gastroenterology 2013;144:S537-S538.

56. Mekjian HS, Phillips SF, Hofmann AF. Colonic secretion of water and electrolytes induced by bile acids: perfusion studies in man. J Clin Invest 1971;50:1569-1577.

57. Bajor A, Gillberg PG, Abrahamsson H. Bile acids: short and long term effects in the intestine. Scand J Gastroenterol 2010;45:645-664.

58. Shin A, Camilleri M, Vijayvargiya P, et al. Bowel functions, fecal unconjugated primary and secondary bile acids, and colonic transit in patients with irritable bowel syndrome. Clin Gastroenterol Hepatol 2013;11:1270-1275, e1.

59. Wong BS, Camilleri M, Carlson P, et al. Increased bile acid biosynthesis is associated with irritable bowel syndrome with diarrhea. Clin Gastroenterol Hepatol 2012;10:1009-1015, e3.

60. Mok HY, Bell GD, Dowling RH. Effect of different doses of chenodeoxycholic acid on bile-lipid composition and on frequency of side- 
effects in patients with gallstones. Lancet 1974;2:253-257.

61. Fromm H, Sarva RP, Ravitch MM, McJunkin B, Farivar S, Amin P. Effects of jejunoileal bypass on the enterohepatic circulation of bile acids, bacterial flora in the upper small intestine, and absorption of vitamin B12. Metabolism 1983;32:1133-1141.

62. Bazzoli F, Malavolti M, Petronelli A, Barbara L, Roda E. Treatment of constipation with chenodeoxycholic acid. J Int Med Res 1983;11:120-123.

63. Odunsi-Shiyanbade ST, Camilleri M, McKinzie S, et al. Effects of chenodeoxycholate and a bile acid sequestrant, colesevelam, on intestinal transit and bowel function. Clin Gastroenterol Hepatol 2010;8:159-165.

64. Wong BS, Camilleri M. Elobixibat for the treatment of constipation. Expert Opin Investig Drugs 2013;22:277-284.

65. Shailubhai K. Therapeutic applications of guanylate cyclase-C receptor agonists. Curr Opin Drug Discov Devel 2002;5:261-268.

66. Bharucha AE, Waldman SA. Taking a lesson from microbial diarrheagenesis in the management of chronic constipation. Gastroenterology 2010;138:813-817.

67. Miner PB, Surowitz R, Fogel R, et al. Plecanatide, a novel guanylate-cyclase $\mathrm{C}(\mathrm{GC}-\mathrm{C})$ receptor agonist, is efficacious and safe in patients with chronic idiopathic constipation (CIC): results from a 951 patient, 12 week, multi-center trial. Digestive Diseases Week 2013, May 21, Orange County Convention Center, Orlando, FL: 925 g.

68. Jadav AM, McMullin CM, Smith J, Chapple K, Brown SR. The association between prucalopride efficacy and constipation type. Tech Coloproctol 2013;17:555-559.

69. De Schryver AM, Andriesse GI, Samsom M, Smout AJ, Gooszen $\mathrm{HG}$, Akkermans LM. The effects of the specific $5 \mathrm{HT}_{4}$ receptor agonist, prucalopride, on colonic motility in healthy volunteers. Aliment Pharmacol Ther 2002;16:603-612.

70. Camilleri M, Van Outryve MJ, Beyens G, Kerstens R, Robinson P, Vandeplassche L. Clinical trial: the efficacy of open-label prucalopride treatment in patients with chronic constipation - follow-up of patients from the pivotal studies. Aliment Pharmacol Ther 2010;32: 1113-1123.

71. Tack J, Camilleri M, Chang L, et al. Systematic review: cardiovascular safety profile of $5-\mathrm{HT}_{4}$ agonists developed for gastrointestinal disorders. Aliment Pharmacol Ther 2012;35:745-767.

72. Cinca R, Chera D, Gruss HJ, Halphen M. Randomised clinical trial: macrogol/PEG $3350+$ electrolytes versus prucalopride in the treatment of chronic constipation - a comparison in a controlled environment. Aliment Pharmacol Ther 2013;37:876-886.

73. Kanazawa M, Watanabe S, Tana C, Komuro H, Aoki M, Fukudo S. Effect of $5-\mathrm{HT}_{4}$ receptor agonist mosapride citrate on rectosigmoid sensorimotor function in patients with irritable bowel syndrome. Neurogastroenterol Motil 2011;23:754, e332.

74. Maneerattanaporn M, Chang L, Chey WD. Emerging pharmaco- logical therapies for the irritable bowel syndrome. Gastroenterol Clin North Am 2011;40:223-243.

75. Mansour NM, Ghaith O, El-Halabi M, Sharara AI. A prospective randomized trial of mosapride vs. placebo in constipation-predominant irritable bowel syndrome. Am J Gastroenterol 2012;107:792793.

76. Spencer AG, Jacobs JW, Leadbetter MR, et al. RDX5791, a first-in-class minimally systemic NHE3 inhibitor in clinical development for CIC and IBS-C, increases intestinal sodium leading to enhanced intestinal fluid volume and transit. Gastroenterology 2011; 140(suppl 1):S99.

77. Coleman NS, Marciani L, Blackshaw E, et al. Effect of a novel 5- $\mathrm{HT}_{3}$ receptor agonist $\mathrm{MKC}-733$ on upper gastrointestinal motility in humans. Aliment Pharmacol Ther 2003;18:1039-1048.

78. Itoh T, Yamakawa J, Mai M, Yamaguchi N, Kanda T. The effect of the herbal medicine dai-kenchu-to on post-operative ileus. J Int Med Res 2002;30:428-432.

79. Takeda T, Kamiura S, Kimura T. Effectiveness of the herbal medicine daikenchuto for radiation-induced enteritis. J Altern Complement Med 2008;14:753-755.

80. Kawasaki N, Nakada K, Nakayoshi T, et al. Effect of Dai-kenchu-to on gastrointestinal motility based on differences in the site and timing of administration. Dig Dis Sci 2007;52:2684-2694.

81. Kawasaki N, Nakada K, Suzuki Y, Furukawa Y, Hanyu N, Kashiwagi H. Effect of Dai-kenchu-to on gastrointestinal motility and gastric emptying. Int J Surg 2009;7:218-222.

82. Borowiec AM, Fedorak RN. The role of probiotics in management of irritable bowel syndrome. Curr Gastroenterol Rep 2007;9:393400.

83. Brenner DM, Moeller MJ, Chey WD, Schoenfeld PS. The utility of probiotics in the treatment of irritable bowel syndrome: a systematic review. Am J Gastroenterol 2009;104:1033-1049.

84. Whorwell PJ, Altringer L, Morel J, et al. Efficacy of an encapsulated probiotic Bifidobacterium infantis 35624 in women with irritable bowel syndrome. Am J Gastroenterol 2006;101:1581-1590.

85. O'Mahony L, McCarthy J, Kelly P, et al. Lactobacillus and bifidobacterium in irritable bowel syndrome: symptom responses and relationship to cytokine profiles. Gastroenterology 2005;128:541-551.

86. Moayyedi P, Ford AC, Talley NJ, et al. The efficacy of probiotics in the treatment of irritable bowel syndrome: a systematic review. Gut 2010;59:325-332.

87. Attaluri A, Donahoe R, Valestin J, Brown K, Rao SS. Randomised clinical trial: dried plums (prunes) vs. psyllium for constipation. Aliment Pharmacol Ther 2011;33:822-828.

88. Chang CC, Lin YT, Lu YT, Liu YS, Liu JF. Kiwifruit improves bowel function in patients with irritable bowel syndrome with constipation. Asia Pac J Clin Nutr 2010;19:451-457. 